\section{The role of the urogynecologist with sphincteroplasty: a multidisciplinary approach to a very common, yet devastating problem}

\author{
Ali Mahmood, ${ }^{1}$ Prianka Gajula² \\ ${ }^{1}$ Clinical Faculty, Department of Surgery, \\ Division of Colon \& Rectal Surgery \\ Colorectal Surgical Associates, \\ The University of Texas Medical School \\ at Houston, Sugar Land, TX, USA; \\ ${ }^{2}$ Colo Liver Gastro Consultants, \\ Sugar Land, TX, USA
}

\section{Abstract}

Fecal incontinence is a disorder that affects many women, particularly those that have been multiparous. Aside from the physical disability, this disorder affects the psychosocial aspect along with issues of self-confidence and self esteem. Sphincteroplasty for fecal incontinence is an operation that has been well described to address this problem and offers great success.

However, there are many patients that suffer from pelvic organ prolapse concurrently, along with fecal incontinence. The pelvic organ prolapse is often amenable to surgical correction; however, many gynecologists prefer to fix this in a setting with minimal fecal contamination, thus obviating a joint and multidisciplinary approach with colorectal surgery.

We present a series of 17 consecutive cases where a sphincteroplasty was performed, with or without a concomitant gynecological procedure for solid organ prolapse.

\section{Materials and Methods}

From February 2009 to December 2010, all consecutive cases of sphincterplasty were retrospectively reviewed. Patients underwent a series of preoperative testing which included anal manometry, ultrasound of the sphincter complex, pudendal nerve terminal motor latency (PNTML) and a thorough physical exam. Following operative intervention, the patients were followed for 10-38 months. Their repair was evaluated in conjunction to their quality of life. Patients that underwent sphincteroplasty in addition to repair of pelvic organ prolapse were included in the study. The patients were evaluated based on age, sex, number of years of fecal incontinence, concurrent pelvic organ prolapse and obesity. They were followed up in the office to determine the degree of satisfaction in comparison to their preoperative evaluation. Patients were given a choice of being highly satisfied, satisfied, equivocal, dissatisfied, or highly dissatisfied.

\section{Results}

There were 17 sphincterplasty patients that were included in our study. 7 patients underwent sphincteroplasty alone. Ten patients underwent sphincteroplasty in concordance with pelvic organ prolapse repair (Figure 1). Among these 10, 8 had urinary bladder prolapse that was repaired and 2 patients had uterine prolapse that was addressed.

The median age of the patients was 67.2 , with a range from 44 to 82 (Figure 2). The patients were all female, with a mean onset of fecal incontinence to be approximately 2 years. The body mass index ranged from 26 to 41 with a mean of 33.8 .

Ultrasonongraphy revealed a sphincter defect in each patient. The manometry studies showed a significant decrease in squeeze pressures, ranging from $6-15$ in the distal third of the anorectal canal. PNTML showed a prolonged time in $8(47 \%)$ of the patients evaluated.

Upon follow up there was a two wound infections that were both treated successfully with antibiotics. Both of these infections were in the cohort of sphincteroplasty alone.

16 of the 17 patients were satisfied with their surgery upon follow up, with 12 patients highly satisfied. Only one patient was slightly dissatisfied with the results of the repair. This single patient underwent urinary bladder prolapse repair along with a anterior sphincteroplasty.

\section{Discussion}

Fecal incontinence is a very serious problem that affects close to $50 \%$ of elderly women in some studies. ${ }^{1}$ Women who suffer from urinary incontinence have an incidence of fecal incontinence ranging from 30 to 50 percent. ${ }^{2,3}$ The incidence of fecal incontinence is higher in women with pelvic organ prolapse. ${ }^{4}$ There have been several studies describing the concomitant repair of pelvic organ prolapse and sphincteroplasty. While the combined operations were technically feasible, the aim of the study was to determine the efficacy of combined repairs along with examining the overall satisfaction and safety of the operation.

All 17 of the patients did not regress from the surgical intervention. The majority of the patients, $16(94.1 \%)$, were at least satisfied with the results. The incidence of infection
Correspondence: Ali Mahmood, Clinical Faculty, Department of Surgery, Division of Colon \& Rectal Surgery Colorectal Surgical Associates, The University of Texas Medical School at Houston, 503 Pickney Ave, Sugar Land, TX 77479 USA. Tel. +1.281.242.3300 - Fax: +1.281.240.0114. E-mail: strikermd@hotmail.com

Key words: incontinence, urogynecology, sphincteroplasty, organ prolapse.

Acknowledgements: the authors would like to thank Dr. Leka Gajula.

Contributions: AM, manuscript developing and case studies performing; $\mathrm{PG}$, manuscript developing and figures and tables providing.

Conflict of interests: the authors declare no potential conflict of interests.

Received for publication: 5 November 2011. Revision received: 5 November 2011. Accepted for publication: 11 May 2012.

This work is licensed under a Creative Commons Attribution NonCommercial 3.0 License (CC BYNC 3.0).

@CCopyright A. Mahmood and P. Gajula, 2012

Licensee PAGEPress, Italy

Urogynaecologia 2012; 26:e6

doi:10.4081/uij.2012.e6

was higher in the sphinceroplasty alone cohort. The benefit of the combined operation includes a single exposure to anesthesia, decreased hospital time and an overall reduction in operative time. There was, however, an increase in single visit operative intervention, i.e. the combined operation did take longer to complete than sphincteroplasty alone.

The etiology of fecal incontinence is attributed largely to adverse effects to pelvic floor musculature and/or pudendal nerve injury. ${ }^{5}$ Childbirth, obstetrical injury and pelvic trauma are the most common causes. Often these cases can be addressed with an anterior sphincteroplasty. ${ }^{6}$ All cases of fecal incontinence in our study were treated with an anterior sphincteroplasty. The rate of wound infection was higher in the sphincteroplasty alone cohort, however this increase in infection was not shown to be statistically significant. Although there have been reports depicting the protective effects of colostomy in healing and wound infection, we did not perform a diverting colostomy in any patient, particularly as there was sufficient data in the literature to dissuade from yet another procedure. ${ }^{7}$

The post-operative satisfaction from surgical repair, both single and combined, was excellent. The vast majority of the patients, $16 / 17$, were satisfied with their repair. The 
10

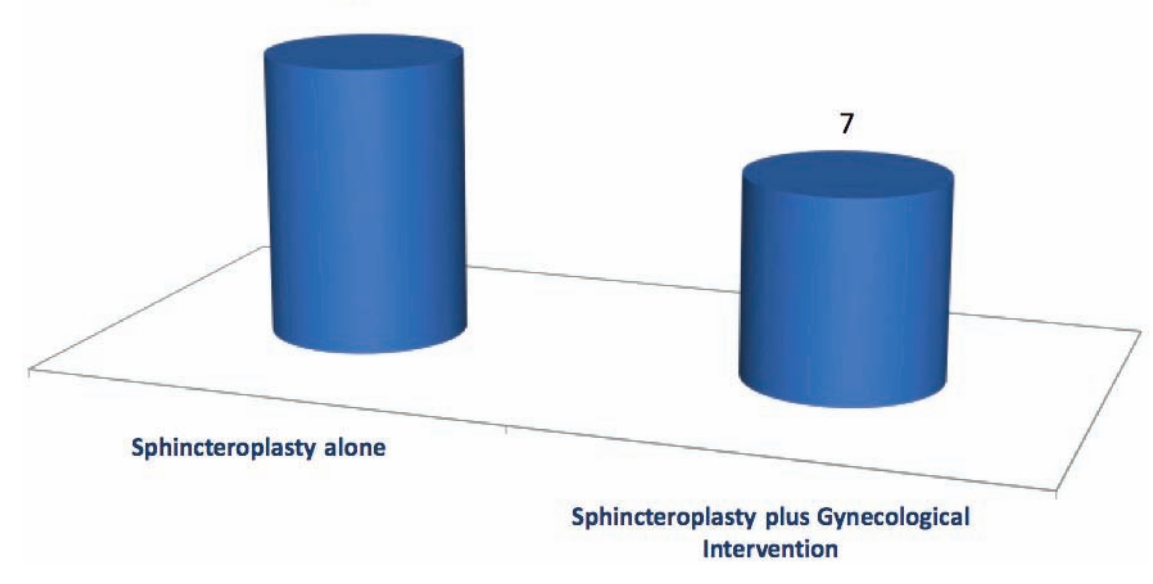

Figure 1. Number of cases in each group.

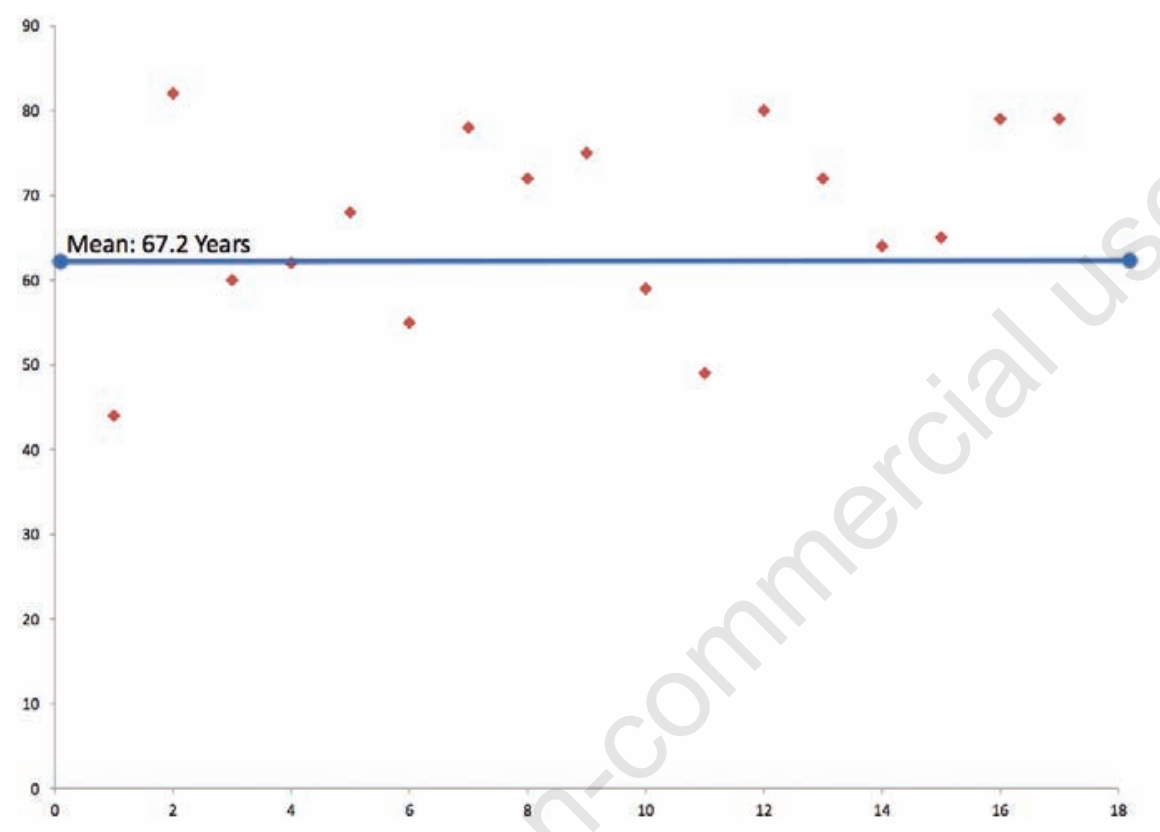

Figure 2. Age distribution of patients.

long-term follow up did not deviate from the initial feeling of content. Pudendal nerve studies, along with anal manometry were obtained in each patient. PNTML was prolonged in 13 (76.5\%) of the patients. Prolonged PNTML following surgery has been shown to be deleterious to repair. 8 The technical aspect of the procedure entailed an overlapping of the anterior aspect of the sphincter without a defined and dedicated perineoplasty, although there are some studies supporting the addition of specific perineal reconstruction to help augment the sphincter repair. ${ }^{9}$

As new technology becomes available in the the results will not reflect the optimal management. Once, however the etiology of the incontinence and the pelvic organ prolapse is correctly identified, we advocate a combined approach for repair.

\section{References}

1. Kok AM, Voorhrst FJ, Burger CW, et al. Urinary and fecal incontinence in community-residing elderly women. Age Aging 1992;21:211-5.

2. Caputo RM, Benson JT. Idiopathic fecal incontinence. Curr Opin Obstet Gynecol 1992;4:565-70.

3. Mcintosh LJ, Frahm JD, Mallett VT, Richardson DA. Pelvic floor rehabilitation in the treatment of incontinence. J Reprod Med 1993;38:662-6.

4. Jackson SL, Weber AM, Hull TL, et al. Fecal incontinence in women with urinary incontinence and pelvic organ prolapse. Obstet Gynecol 1997;89:423-7.

5. Snooks SJ, Stechell M, Swash M, Henry MM. Injury to innervation of pelvic floor sphincter musculature in childbirth. Lancet 1984;2:546-50.

6. Barisic G, Krivokapic Z, Markovic V, et al. The role of overlapping sphincteroplasty in traumatic fecal incontinence. Acta Chir Iugols 2000;47:37-41.

7. Nessim A, Wexner SD, Agachan F, et al. Is bowel confinement necassry after anorectal reconstructive surgery? A prospective, randomized, surgeon-blinded trial. Dis Colon Rectum 1999;42:16-23.

8. Gilliland R, Altomare DF, Moreira $\mathrm{H} \mathrm{Jr}$, et al. Pudendal neuropathy is predictive of failure following anterior overlapping sphincteroplasty. Dis Colon Rectum 1998; 41:1516-22.

9. Novi JM, Mulvihill BH, Morgan MA. Combined anal sphincteroplasty and perineal reconstruction for fecal incontinence in women. J Am Osteopath Assoc 2009;109: 234-6.

10. Oom DM, Gosselink MP, Schouten WR. Anterior sphincteroplasty for fecal incontinence: a single center experience in the era of sacral neuromodulation. Dis Colon Rectum 2009;52:1681-7.

11. Pearson B, Wexner SD. Advances in the surgical treatment of fecal incontinence. Surg Innov 2005;12:7-21.

12. Chase S, Mittal R, Jesudason MR, et al. Anal sphincter repair for fecal incontinence: experience from a tertiary care center. Indian J Gastroenterol 2010;29: 162-5. 